UDK 782.1(437) Janáček

\title{
UGOTAVLJANJE TIPIČNOSTI \\ NEKATERIH MELODIČNIH STRUKTUR V VOKALNI MELODIKI JANÁČKOVE OPERE »SLUČAJ MAKROPULOS«
}

Miloš $\mathrm{S}$ t ědron (Brno)

Še preden objavimo izsledke delne kompjuterske sonde na področju tipičnosti določenih Janáčkovih struktur, je potrebno na kratko informirati o smislu celotnega projekta, ki je v njem ta sonda samo eden izmed faktorjev. V bistvu gre za to, da sem skupaj s sodelavcem Arnoštom Parschom in z brnskima matematikoma Jiříjem Kopřivo in Janom Dvořákom izdelal projekt analize vokalne melodike Janáčkove opere »Slučaj Makropulos«. Ta projekt je tičal v tem, da je bila melodika celotne opere po posameznih vokalnih vlogah predpisana $\mathrm{s}$ kodeksom, ki je izražal intervalne odnose. Melodični tekst posameznih vlog smo razdelili $\mathrm{v}$ modele tako, da smo uvedli večjo pavzo kot so tričetrtinske pavze, ne oziraje se na metrum segmenta. Sleherna pavza, večja od tričetrtinske vrednote, je bila signal za pretrganje linije. Tako je ves tekst razpadel na celo vrsto modelov. Vzrok za tak ukrep je bila potreba pripravljati kompjutersko analizo z maksimalno petnajstčlenskimi modeli, to pa glede na kompjuterski spomin. Janáčkova melodika je tvorba modelov z nizkim številom lastnih členov. Zahteva po petnajstčlenskem modelu skoraj ni bila prekoračena. Melodični tekst je bil zapisovan numerično, to pa tako, da je sleherni dvigajoči se in padajoči interval ohranil adekvatno numerično znamenje: dvigajoča se mala sekunda $=+1$, dvigajoča se velika sekunda $=+2$, dvigajoča se mala terca $=+3$, dvigajoča se velika terca $=+4$; padajoča mala sekunda $=-1$, padajoča velika sekunda $=-2$, padajoča mala terca $=-3$, padajoča velika terca $=-4$ itd. Interval prime je bil izražen $\mathrm{z}$ znakom 0 . Interval med zadnjim tonom modela in prvim tonom naslednjega modela smo označili kot "mrtvi« interval in smo ga znotraj registrirali pred začetkom slehernega modela. Posamezne vloge so bile označene $\mathbf{z}$ arabskimi številkami in sicer takole: Emilia Marty $=1$, Gregor $=2$, dr. Kolenatý $=3$, Vítek $=4$, baron Prus $=5$, Kristina $=6$, Snažilka $=$ $=7$, Strojnik $=8$, Janek $=9$, Hauk $=10$, Sobarica $=11$, Služkinja $=$ $=12$. $\mathrm{Z}$ določitvijo transkripcijskih načel in po konzultacijah $\mathrm{z}$ mate- 
matiki je nastal takoimenovani transkripcijski katalog vseh vlog po posameznih modelih. Kot primer navajamo popolno podobo treh modelov. Na podlagi teh primerov si lahko ustvarimo natančno predstavo o numerični transkripciji vokalne melodike.

Primer:

$\begin{array}{ccccc}\text { Vloga } & \text { Dejanje } & \text { Model } & \text { Mrtvi interval } & \text { Intervali } \\ 1 & 1 & 1 & 0 & +5+2-7+2+5 \\ 1 & 1 & 2 & -4 & +4-5 \\ 1 & 1 & 3 & +5 & -5-9+2+1+3+1 \\ & & & & +3+4-5\end{array}$

V končni pripravi transkripcijskega kataloga smo zaznamovali zgolj zanikovalna znamenja intervalov (intervali brez znamenja so potemtakem avtomatično veljali za pozitivne); pri traskripciji je bilo prav tako opuščeno zaznamovanje intervalov prime $=0$. Tako se je bistveno okrajšal tekst, ne da bi se izpridilo modeliranje intervalne strukture. Interval 0 bo po odločitvi avtorjev projekta ovrednoten zunaj področja kompjuterske analize glede na to, da gre za statistično, nikakor pa ne za zapleteno zadevo.

Po razčlembi celotnega teksta so bile in so doslej izpeljane in obdelane naslednje analitične sonde iz celotnega kompleksa vokalne melodije te opere:

1. Ugotovitev celotnega števila vsakega intervala v celotni operi, tako $\mathrm{v}$ posameznih dejanjih kakor $\mathrm{v}$ posameznih vlogah po posameznih dejanjih.

2. Klasificiranje dvigajočih se in padajočih intervalov; ugotavljanje »stopnjevanja posameznih modelov; "stopnjevanje» posameznih vlog.

3. Ugotavljanje simetričnih in asimetričnih odnosov v modelih; uporaba možnosti, da se vsi modeli izrazijo s formo melodične krivulje.

4. Ugotavljanje verjetnosti pojava posameznih intervalov po slehernem intervalu (ugotovitev vsakega prvega, drugega, tretjega do četrtega intervala, nastopajočega neposredno po slehernem intervalu teksta in določanje verjetnosti pojava).

5. Razvrstitev modelov po dolžini in intervalnem obsegu (katalog tonskih skupin s pomočjo njihovih intervalnih podob).

6. Ugotavljanje pojava tako imenovanih domnevnih janáčkovskih struktur $\mathrm{v}$ celotnem tekstu opere in kontrola njihove tipičnosti.

7. Ugotavljanje semantične vsebine istovetnih modelov (odnos teksta libreta opere do njene melodične in intervalne vrste).

Doslej sta bili publicirani dve delni študiji o projektu: Miloš Štědroň, Možnosti intervalové a melodické analýzy-Sonda do intervalové a melodické analýzy Janáčkovy opery Věc Makropulos-role Hauka, Opus musicum 7/71, 202-208; isti, $\mathrm{K}$ analýze vokální melodiky Janáčkovy opery Věc Makropulos s využitím samočinného počí- 
tače, Hudební věda. Prva izmed navedenih študij daje podrobnejše informacije o projektu in prikazuje na eni sami vlogi analitične posege, $\mathrm{v}$ katere bo pri analizi celotnega vokalnega gradiva vključen kompjuter. Druga študija prinaša celotne izsledke kompjuterske analize, kolikor se tiče sonde 1 .

Po tej predhodni informaciji je mogoče preiti $\mathrm{k}$ vsebini naše študije. Tu gre za sondo št. 6 - za ugotovitev pojava domnevnih janáčkovskih struktur $\mathrm{v}$ celotnem tekstu te opere, to pa $\mathrm{s}$ pomočjo kompjuterja in za kontrolo njihove tipičnosti. Avtor študije je ugotovil 21 domnevnih takih struktur. Te kratke, večidel tritonske strukture so bile izpeljane analogno iz janáčkovskih analiz kot tipični izrazi njegovega melodičnega mišljenja. Kompjuter je ugotovil frekvenco in razvrščenost teh struktur $\mathrm{v}$ celotnem tekstu opere in potrdil ali zavrnil njih tipičnost. Zdaj navajamo izsledke te sonde za 21 tako imenovanih tipičnih domnevnih janáčkovskih struktur, označenih s številkami I-XXI.

\begin{tabular}{|c|c|c|c|c|c|}
\hline & $\begin{array}{l}\text { Stevilo } \\
\text { pojavov } \\
\text { v celoti }\end{array}$ & $\begin{array}{l}\text { Iz te } \\
\text { vloge }\end{array}$ & $\begin{array}{l}\text { Število } \\
\text { pojavov }\end{array}$ & Dejanje & $\begin{array}{l}\text { Število } \\
\text { pojavov }\end{array}$ \\
\hline \multicolumn{6}{|l|}{ I } \\
\hline \multirow[t]{3}{*}{ Struktura $-5-2$} & \multirow[t]{13}{*}{20} & 1 & 3 & 1 & 1 \\
\hline & & & & 2 & 1 \\
\hline & & & & 3 & 1 \\
\hline \multirow{10}{*}{$\frac{20 .}{0}$} & & 2 & 3 & 1 & 2 \\
\hline & & & & 2 & 1 \\
\hline & & 3 & 2 & 1 & 2 \\
\hline & & 4 & 2 & 1 & 2 \\
\hline & & 5 & 3 & 2 & 2 \\
\hline & & & & 3 & 1 \\
\hline & & 6 & 2 & 1 & 1 \\
\hline & & & & 2 & 1 \\
\hline & & 9 & 2 & 2 & 2 \\
\hline & & 10 & 3 & 2 & 3 \\
\hline \multicolumn{6}{|l|}{ II } \\
\hline \multirow[t]{3}{*}{ Struktura $-2-5$} & \multirow[t]{12}{*}{36} & 1 & 17 & 1 & 2 \\
\hline & & & & 2 & 8 \\
\hline & & & & 3 & 7 \\
\hline$\hat{z}$ & & 2 & 10 & 1 & 8 \\
\hline \multirow{8}{*}{0} & & & & 2 & 1 \\
\hline & & & & 3 & 1 \\
\hline & & 3 & 1 & 1 & 1 \\
\hline & & 5 & 3 & 2 & 3 \\
\hline & & 6 & 2 & 1 & 1 \\
\hline & & & & 2 & 1 \\
\hline & & 8 & 2 & 2 & 2 \\
\hline & & 9 & 1 & 2 & 1 \\
\hline
\end{tabular}




\begin{tabular}{|c|c|c|c|c|c|}
\hline & $\begin{array}{l}\text { Stevilo } \\
\text { pojavov } \\
\text { v celoti }\end{array}$ & $\begin{array}{l}\text { Iz te } \\
\text { vloge }\end{array}$ & $\begin{array}{l}\text { Število } \\
\text { pojavov }\end{array}$ & Dejanje & $\begin{array}{l}\text { število } \\
\text { pojavov }\end{array}$ \\
\hline \\
\hline Struktura $-5-1$ & \multirow[t]{4}{*}{5} & 1. & 2 & $\begin{array}{l}1 \\
3\end{array}$ & 1 \\
\hline \multirow{2}{*}{$\frac{1}{20}$} & & 2 & \multirow[t]{2}{*}{2} & 1 & 1 \\
\hline & & & & 2 & 1 \\
\hline 0 & & 3 & \multirow[t]{2}{*}{1} & 1 & 1 \\
\hline \multicolumn{5}{|l|}{ IV } & \\
\hline Struktura $-1-5$ & \multirow[t]{4}{*}{6} & 1 & 3 & $\begin{array}{l}1 \\
2\end{array}$ & $\begin{array}{l}1 \\
1\end{array}$ \\
\hline 2 & & \multirow{3}{*}{3} & \multirow{3}{*}{3} & 3 & 1 \\
\hline \multirow{2}{*}{ 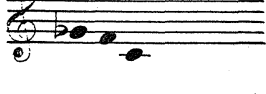 } & & & & 1 & 2 \\
\hline & & & & 3 & 1 \\
\hline \multicolumn{6}{|l|}{ V } \\
\hline \multirow{3}{*}{ Struktura $-4-2$} & \multirow[t]{12}{*}{26} & 1 & 9 & 1 & 2 \\
\hline & & & & 2 & 4 \\
\hline & & & & 3 & 3 \\
\hline \& & & 2 & 1 & 1 & 1 \\
\hline \multirow{8}{*}{ to. } & & 3 & 3 & 1 & 1 \\
\hline & & & & 3 & 2 \\
\hline & & 4 & 1 & 2 & 1 \\
\hline & & 5 & 6 & 1 & 1 \\
\hline & & & & 2 & 3 \\
\hline & & & & 3 & 2 \\
\hline & & 6 & 5 & 2 & 5 \\
\hline & & 11 & 1 & 3 & 1 \\
\hline \multicolumn{6}{|l|}{ VI } \\
\hline \multirow[t]{3}{*}{ Struktura $-2-4$} & \multirow[t]{12}{*}{25} & 1 & 9 & 2 & 3 \\
\hline & & & & 3 & 6 \\
\hline & & 2 & 4 & 1 & 3 \\
\hline & & & & 2 & 1 \\
\hline \multirow{8}{*}{ e } & & 3 & 2 & 1 & 2 \\
\hline & & 4 & 1 & 1 & 1 \\
\hline & & 5 & 3 & 2 & 1 \\
\hline & & & & 3 & 2 \\
\hline & & 6 & 1 & 2 & 1 \\
\hline & & 8 & 1 & 2 & 1 \\
\hline & & 10 & 2 & 2 & 2 \\
\hline & & 11 & 2 & 3 & 2 \\
\hline
\end{tabular}

8 


\begin{tabular}{l|c|c|c|c}
\hline $\begin{array}{c}\text { Stevilo } \\
\text { pojavov } \\
\text { v celoti }\end{array}$ & $\begin{array}{c}\text { Iz te } \\
\text { vloge }\end{array}$ & $\begin{array}{c}\text { Stevilo } \\
\text { pojavov }\end{array}$ & Dejanje & $\begin{array}{c}\text { Stevilo } \\
\text { pojavov }\end{array}$ \\
\hline
\end{tabular}

VII

Struktura -3-2

43

$\begin{array}{rlll}1 & 15 & 1 & 6 \\ & & 2 & 4 \\ 2 & 9 & 3 & 5 \\ & & 2 & 7 \\ 3 & 7 & 1 & 2 \\ & & 3 & 3 \\ 4 & 1 & 1 & 1 \\ 5 & 2 & 2 & 2 \\ 6 & 3 & 1 & 3 \\ 7 & 1 & 2 & 1 \\ 9 & 1 & 2 & 1 \\ 10 & 1 & 2 & 1 \\ 11 & 3 & 3 & 3\end{array}$

VIII

Struktura $-2-3$

47

$\begin{array}{cccc}1 & 13 & 1 & 3 \\ & & 2 & 4 \\ 2 & 15 & 3 & 6 \\ & & 2 & 9 \\ & & 3 & 3 \\ 3 & 5 & 1 & 4 \\ & & 3 & 1 \\ 4 & 3 & 1 & 2 \\ & & 3 & 1 \\ 5 & 4 & 2 & 4 \\ 6 & 3 & 1 & 1 \\ & & 2 & 2 \\ 7 & 1 & 2 & 1 \\ 8 & 2 & 2 & 2 \\ 10 & 1 & 2 & 1\end{array}$

IX

Struktura $-2-2-2$

7

$\begin{array}{llll}1 & 3 & 2 & 1 \\ 2 & 1 & 3 & 2 \\ 6 & 3 & 1 & 1 \\ & & 2 & 2\end{array}$

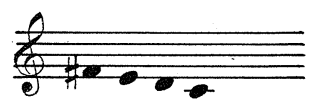

7.




\begin{tabular}{|c|c|c|c|c|c|}
\hline & $\begin{array}{l}\text { Stevilo } \\
\text { pojavov } \\
\text { v celoti }\end{array}$ & $\begin{array}{l}\text { Iz te } \\
\text { vloge }\end{array}$ & $\begin{array}{l}\text { Število } \\
\text { pojavov }\end{array}$ & Dejanje & $\begin{array}{l}\text { Število } \\
\text { pojavov }\end{array}$ \\
\hline $\begin{array}{l}\text { X } \\
\text { Struktura }-2-3-2 \\
\frac{0}{-}\end{array}$ & 11 & $\begin{array}{l}1 \\
2 \\
3 \\
5 \\
6\end{array}$ & $\begin{array}{l}4 \\
2 \\
1 \\
1\end{array}$ & $\begin{array}{l}1 \\
2 \\
3 \\
1 \\
2 \\
1 \\
2 \\
1\end{array}$ & $\begin{array}{l}1 \\
1 \\
1 \\
3 \\
1 \\
2 \\
1 \\
1\end{array}$ \\
\hline $\begin{array}{l}\text { XI } \\
\text { Struktura }-3-2-2-3\end{array}$ & 1 & 2 & 1 & 1 & 1 \\
\hline $\begin{array}{l}\text { XII } \\
\text { Struktura }+5+2\end{array}$ & 22 & $\begin{array}{r}2 \\
3 \\
4 \\
5 \\
10\end{array}$ & $\begin{array}{l}4 \\
4 \\
1 \\
2 \\
1\end{array}$ & $\begin{array}{l}1 \\
2 \\
3 \\
1 \\
2 \\
1 \\
3 \\
1 \\
3 \\
2\end{array}$ & $\begin{array}{l}1 \\
4 \\
5 \\
3 \\
1 \\
1 \\
3 \\
1 \\
2 \\
1\end{array}$ \\
\hline $\begin{array}{l}\text { XIII } \\
\text { Struktura }+2+5\end{array}$ & 20 & $\begin{array}{l}2 \\
3 \\
4 \\
5 \\
6\end{array}$ & $\begin{array}{l}1 \\
4 \\
1 \\
2 \\
1\end{array}$ & $\begin{array}{l}1 \\
2 \\
3 \\
1 \\
1 \\
3 \\
1 \\
2 \\
2\end{array}$ & $\begin{array}{l}1 \\
3 \\
7 \\
1 \\
2 \\
2 \\
1 \\
2 \\
1\end{array}$ \\
\hline $\begin{array}{l}\text { XIV } \\
\text { Struktura }+5+1 \\
\text { D }\end{array}$ & 3 & 1 & 3 & $\begin{array}{l}1 \\
2\end{array}$ & $\begin{array}{l}1 \\
2\end{array}$ \\
\hline
\end{tabular}

10 


\begin{tabular}{|c|c|c|c|c|c|}
\hline & $\begin{array}{l}\text { Število } \\
\text { pojavov } \\
\text { v celoti }\end{array}$ & $\begin{array}{l}\text { Iz te } \\
\text { vloge }\end{array}$ & $\begin{array}{l}\text { Število } \\
\text { pojavov }\end{array}$ & Dejanje & $\begin{array}{l}\text { Število } \\
\text { pojavov }\end{array}$ \\
\hline \multicolumn{6}{|l|}{ XV } \\
\hline Struktura $+1+5$ & 9 & 1 & 6 & $\begin{array}{l}1 \\
2\end{array}$ & $\begin{array}{l}2 \\
3\end{array}$ \\
\hline \multirow{2}{*}{$Z^{-}$} & & & & 3 & 1 \\
\hline & & 2 & 1 & 2 & 1 \\
\hline \multirow{2}{*}{$e^{20}$} & & 6 & 1 & 2 & 1 \\
\hline & & 10 & 1 & 3 & 1 \\
\hline \multicolumn{6}{|l|}{ XVI } \\
\hline \multirow{3}{*}{ Struktura $+4+2$} & 14 & 1 & 2 & 1 & 1 \\
\hline & & & & 3 & 1 \\
\hline & & 2 & 3 & 1 & 3 \\
\hline 2 & & 3 & 4 & 1 & 2 \\
\hline \multirow{4}{*}{ 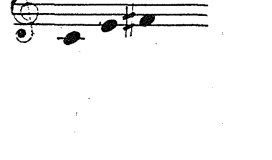 } & & & & 3 & 2 \\
\hline & & 4 & 2 & 1 & 2 \\
\hline & & 5 & 2 & 3 & 2 \\
\hline & & 6 & 1 & 1 & 1 \\
\hline \multicolumn{6}{|l|}{ XVII } \\
\hline \multirow[t]{2}{*}{ Struktura $+2+4$} & 17 & 1 & 5 & 1 & 1 \\
\hline & & & & 2 & 4 \\
\hline 2 & & 2 & 4 & 1 & 3 \\
\hline \multirow{5}{*}{$\frac{1}{0.0}$} & & 3 & 3 & $\begin{array}{l}2 \\
1\end{array}$ & $\begin{array}{l}1 \\
1\end{array}$ \\
\hline & & & & 3 & 2 \\
\hline & & 4 & 3 & 1 & 3 \\
\hline & & 6 & 1 & 2 & 1 \\
\hline & & 11 & 1 & 3 & 1 \\
\hline \multicolumn{6}{|l|}{ XVIII } \\
\hline \multirow{2}{*}{ Struktura $+3+2$} & 45 & 1 & 9 & 1 & 2 \\
\hline & & & & 2 & 6 \\
\hline \multirow{11}{*}{$\frac{1}{200}$} & & & & 3 & 1 \\
\hline & & 2 & 13 & 1 & 9 \\
\hline & & & & $\begin{array}{l}2 \\
3\end{array}$ & 2 \\
\hline & & 3 & 7 & 1 & $\begin{array}{l}2 \\
4\end{array}$ \\
\hline & & & & 3 & 3 \\
\hline & & 5 & 11 & 1 & 1 \\
\hline & & & & 2 & 9 \\
\hline & & & & 3 & 1 \\
\hline & & 6 & 2 & 1 & 2 \\
\hline & & 8 & 1 & 2 & 1 \\
\hline & & 10 & 2 & 3 & 2 \\
\hline
\end{tabular}




\begin{tabular}{|c|c|c|c|c|c|}
\hline & $\begin{array}{l}\text { Stevilo } \\
\text { pojavov } \\
\text { v celoti }\end{array}$ & $\begin{array}{l}\text { Iz te } \\
\text { vloge }\end{array}$ & $\begin{array}{l}\text { Število } \\
\text { pojavov }\end{array}$ & Dejanje & $\begin{array}{l}\text { Stevilo } \\
\text { pojavov }\end{array}$ \\
\hline \multicolumn{6}{|l|}{ XIX } \\
\hline Struktura $+2+3$ & 44 & 1 & 18 & $\begin{array}{l}1 \\
2 \\
3\end{array}$ & $\begin{array}{l}6 \\
7 \\
5\end{array}$ \\
\hline \multirow{11}{*}{$\frac{2}{20}$} & & 2 & 5 & $\begin{array}{l}3 \\
1\end{array}$ & $\begin{array}{l}5 \\
3\end{array}$ \\
\hline & & & & $\begin{array}{l}2 \\
3\end{array}$ & 1 \\
\hline & & 3 & 7 & 1 & 5 \\
\hline & & & & 3 & 2 \\
\hline & & 4 & 1 & 2 & 1 \\
\hline & & 5 & 6 & 2 & 4 \\
\hline & & & & 3 & 2 \\
\hline & & 6 & 5 & 1 & 4 \\
\hline & & & & 2 & 1 \\
\hline & & 9 & 1 & 2 & 1 \\
\hline & & 11 & 1 & 3 & 1 \\
\hline \multicolumn{6}{|l|}{$\mathrm{XX}$} \\
\hline Struktura $+2+2+2$ & 5 & 1 & 2 & $\begin{array}{l}2 \\
3\end{array}$ & $\begin{array}{l}1 \\
1\end{array}$ \\
\hline \multirow{2}{*}{$\frac{2}{2-0.0}$} & & 3 & 1 & 3 & 1 \\
\hline & & 5 & 1 & 2 & 1 \\
\hline 0.01 & & 6 & 1 & 1 & 1 \\
\hline \multicolumn{6}{|l|}{ XXI } \\
\hline \multirow[t]{3}{*}{ Struktura $+2+3+2$} & 10 & 1 & 2 & $2^{\prime}$ & 2 \\
\hline & & 2 & 1 & 2 & 1 \\
\hline & & 3 & 2 & 1 & 1 \\
\hline \multirow{3}{*}{$\frac{\hat{t}}{0.0}$} & & & & 3 & 1 \\
\hline & & 5 & 3 & 2 & 2 \\
\hline & & & & 3 & 1 \\
\hline & & 0 & & & \\
\hline
\end{tabular}


Vrednotenje analize:

Izsledke, ki smo jih pridobili s kompjuterjem, uvrščamo v naslednjo tabelo:

A

Strukture $\mathrm{z}$ največjim pojavom

$$
\begin{aligned}
& -2-3: 47 \times \\
& +3+2: 45 \times \\
& +2+3: 44 \times \\
& -3-2: 43 \times \\
& -2-5: 36 \times \\
& -4-2: 26 \times \\
& -2-4: 25 \times \\
& +5+2: 22 \times \\
& -5-2: 20 \times \\
& +2+5: 20 \times \\
& +2+4: 17 \times
\end{aligned}
$$

B

Strukture $\mathrm{s}$ povprečnim pojavom $\mathrm{z}$ najmanjšim pojavom

$$
\begin{array}{r}
+4+2: 14 \times \\
-2-3-2: 11 \times \\
+2+3+2: 10 \times \\
+1+5: 9 \times \\
-2-2-2: 5 \times \\
-1-5: 5 \times \\
-2-2-2: 5 \times \\
-5-1: 5 \times
\end{array}
$$

C Strukture

$+5+1: 3 \times$
$-3-2-2-3: 1 \times$

Iz tabele je videti, da je prevladujoča melodična struktura vokalne melodike opere "Slučaj Makropulos« kombinacija velike sekunde $\mathrm{z}$ malo terco. Nasprotja smeri $(-2-3$ in $+2+3:+3+2$ in -3-2) so v pojavu redkokdaj izravnana. Prevladujoči melodični tipi opere so potemtakem tile:

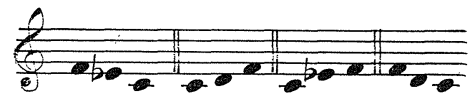

Ponekod manj pogostna, toda kar zadeva pojav, takisto tipična je melodika, ki je nastala $\mathrm{s}$ kombinacijo velike sekunde in čiste kvarte ter velike sekunde in velike terce. Sem sodi tudi Janáčkova vseživljenjska melodična konstanta $(+5+2)$ in kombinacija velike sekunde in velike terce $(-4-2 ;-2-4 ;+2+4 ;+4+2)$ :

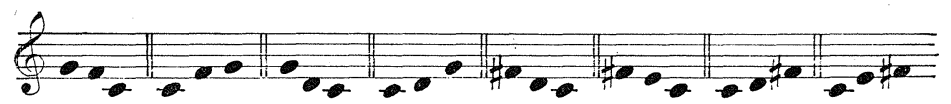

Izseki pentatonike in celotne lestvice ter kombinacije čiste kvarte in male sekunde so manj tipične.

Lahko torej sklepamo:

$\mathrm{V}$ vokalni melodiki opere prevladuje tip, ki je nastal $\mathrm{z}$ veliko sekundo in malo terco. Kombinacija tega izseka pentatonike je osnoven melodični obrat. Če lahko vidimo $\mathrm{v}$ tem sekundnoterčnem in terčnosekundnem izseku pentatonike tipičen melodični obrat, tedaj je povečevanje pentatonike $s$ pridobivanjem nadaljnjih tonov čedalje manj tipično (npr. $-2-3-211 \times$; +2+3+2 $10 \times$; $-3-2-2-3$ $1 \times)$. Janáčkov priljubljeni melodični tip $+5+2$ in njegove kombinacije tudi v nasprotno smer je $\mathrm{v}$ melodiki opere le srednje zastopan. Intervalna diminucija tega tipa - tip $+1+5,-1-5,-5-1,+5+1$ 
je, kar zadeva pojav, netipična; podobna temu primeru je tedaj, če nastopi izsek celotonske lestvice.

Analitična sonda, ki smo jo izpeljali, je pokazala, da je mogoče $s$ pomočjo kompjuterja ugotoviti tipičnost ali netipičnost kakršnihkoli struktur $\mathrm{v}$ transkribiranem tekstu. Ugodnost tega postopka je v možnosti kontrole eventualnih starejših in prejšnjih izsledkov, kolikor jim je šlo za določitev določenih melodičnih tipov na podlagi analize večjega števila glasbenih informacij nekega kroga. Naša sonda je pokazala, da je $\mathrm{v}$ danem primeru sekundnoterčna melodika daleč najbolj tipična za ustvarjanje vokalne linije. Navadno akcentirani tip $+2+5$ in njegova kombinacija sta $v$ danem primeru samo povprečno tipična. Prav tako je zanimivo, h kakšnemu soglasju nasprotujočih si smeri prihaja glede števila takih pojavov (pretehtanost, proporcionalnost usmerjanja melodije). Na splošno velja spoznanje, da so bolj tipične dvointervalne (tritonske) skupine (strukture). Z naraščajočim številom tonov pa slabi tipičnost strukture.

\section{SUMMARY}

The analytical probe undertaken shows that computer techniques make it possible to establish typical and atypical structures in transcribed texts. In the example given the vocal line consists mostly of seconds and thirds. The simply accentuated type $+5+2$, with its combinations, is only an average phenomenon. On the whole, groups of three tones are more typical. With the growing number of tones the structure becomes less typical. 